\title{
Phase constitution, microstructure and mechanical properties of a Ni-based superalloy specially designed for additive manufacturing
}

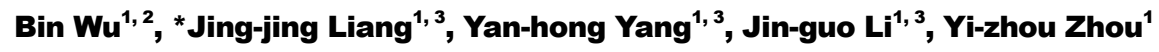 \\ 1. Shi-changxu Innovation Center for Advanced Materials, Institute of Metal Research, Chinese Academy of Sciences, Shenyang 110016, China \\ 2. School of Materials Science and Engineering, University of Science and Technology of China, Shenyang 110016, China \\ 3. Space Manufacturing Technology (CAS Key Lab), Beijing 100094, China
}

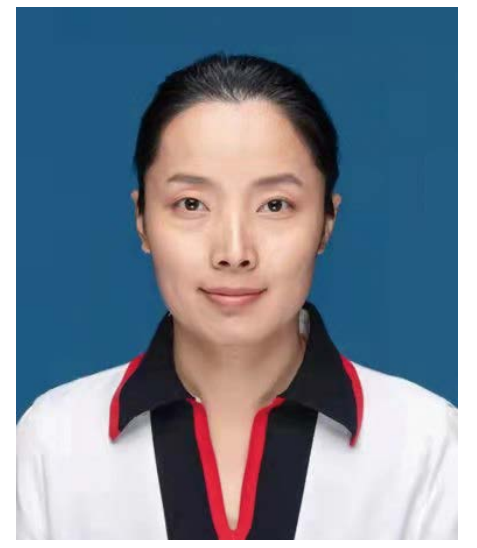

\section{*Jing-jing Liang}

Female, Ph.D., Associate Researcher. Her research interests mainly focus on superalloy composition design and process optimization for additive manufacturing. Dr. Liang has presided more than 10 projects, including the projects supported by the National Science Foundation of China and the Primary Research \& Development plan of Liaoning Province. She has published more than 30 research papers in journals and possesses 22 invention patents of China.

E-mail: jjliang@imr.ac.cn

First author: Bin Wu

E-mail: bwu16b@imr.ac.cn
Abstract: In this study, a kind of Ni-based superalloy specially designed for additive manufacturing (AM) was investigated. Thermo-Calc simulation and differential scanning calorimetry (DSC) analysis were used to determine phases and their transformation temperature. Experimental specimens were prepared by laser metal deposition (LMD) and traditional casting method. Microstructure, phase constitution and mechanical properties of the alloy were characterized by scanning electron microscopy (SEM), transmission scanning electron microscopy (TEM), X-ray diffraction (XRD) and tensile tests. The results show that this alloy contains two basic phases, $\gamma / \gamma^{\prime}$, in addition to these phases, at least two secondary phases may be present, such as MC carbides and Laves phases. Furthermore, the as-deposited alloy has finer dendrite, its mean primary dendrite arm space (PDAS) is about 30-45 $\mu \mathrm{m}$, and the average size of $\mathrm{Y}^{\prime}$ particles is $100-150 \mathrm{~nm}$. However, the dendrite size of the as-cast alloy is much larger and its PDAS is $300-500 \mu \mathrm{m}$ with secondary and even third dendrite arms. Correspondingly, the alloy displays different tensile behavior with different processing methods, and the as-deposited specimen shows better ultimate tensile stress $(1,085.7 \pm 51.7 \mathrm{MPa})$, yield stress $(697 \pm 19.5 \mathrm{MPa})$ and elongation $(25.8 \% \pm 2.2 \%)$ than that of the as-cast specimen. The differences in mechanical properties of the alloy are due to the different morphology and size of dendrites, $\gamma^{\prime}$, and Laves phase, and the segregation of elements, etc. Such important information would be helpful for alloy application as well as new alloy development.

Key words: additive manufacturing; laser metal deposition; Ni-based superalloy; tensile behavior

CLC numbers: TG146.1 5; Document code: A; Article ID: 1672-6421 2021 04-397-12

\section{Introduction}

Ni-based superalloys are widely used to prepare components such as aerospace turbine blades and ground gas-turbine engine blades because they have an exceptional combination performance of high-temperature strength, good toughness, and high resistance to degradation in corrosive or oxidizing environments ${ }^{[1]}$. However, there are varied shortcomings when manufacturing superalloy components by conventional techniques. For example, casting limits the possibility of achieving a superalloy of full potential due to its coarse microstructure, macro-segregation, porosities, and microshrinkages ${ }^{[2]}$. Furthermore, prior particle boundary (PPB) in a superalloy prepared through powder metallurgy decreases its mechanical properties by initiating cracks from the interface easily ${ }^{[3]}$, and, it is difficult to produce the parts by means of a process such as forging because the alloy has lower ductility at lower temperature ${ }^{[4]}$.

Additive manufacturing (AM), also called 3D printing, has the ability to produce components with complex structural shapes that are difficult or impossible to be fabricated by conventional means, so it has become a new technical route for the 
preparation of superalloy components ${ }^{[5-9]}$. Although some disadvantages brought by conventional techniques can be eliminated by AM, there are still key problems needing to be solved before it is used in industry in a large scale. One of the important issues is its thermally induced residual stress and micro-cracking during processing. Quite a few Ni-based superalloys have been documented as being susceptible to micro-cracking, which prevents their application in the manufacture of aerospace components ${ }^{[6,10,11]}$.

To take the advantages of AM and promote the popularization and application of the technology, the development of a special materials system for AM is necessary. The development of a new material should take into consideration both the high performance of materials and the workability for 3D printing ${ }^{[12]}$. In this study, a newly developed Ni-based superalloy is provided to meet the practical requirements. LMD (laser metal deposition or laser melting deposition) ${ }^{[2,9,13-17]}$, currently one of the most popular AM techniques for superalloy manufacturing, is used to prepare experimental specimens.

It is known that the properties of materials are closely related to the microstructure, which depends on the manufacturing process of the alloy. Therefore, the phase, microstructure and properties of the newly designed alloy should be made clear as well as its manufacturing process parameters. By means of Thermo-Calc simulation and differential scanning calorimetry (DSC) analysis, the formation temperatures of main phases and solidification sequence were investigated, which is especially convenient and economical and has proved to be successful in investigating a superalloy ${ }^{[18-20]}$. Tensile tests of both the asdeposited sample (prepared by LMD) and the as-cast sample (prepared by casting process) were performed to compare the property. In addition, scanning electron microscopy (SEM), transmission scanning electron microscopy (TEM), and X-ray diffraction (XRD) were used for microstructure characterization and phase analysis.

\section{Experimental procedures}

\subsection{Sample preparation}

The powder composition of the newly developed alloy is shown in Table 1. The powder is prepared by argon atomization. Its morphology and size distribution are shown in Fig. 1.

Table 1: Chemical composition of superalloy powder (wt.\%)

\begin{tabular}{ccccc} 
Ni & $\mathrm{Al+Ti}$ & $\mathrm{Co}+\mathrm{Cr}$ & $\mathrm{Hf}+\mathrm{Mo}+\mathrm{Nb}$ & $\mathrm{Si}+\mathrm{C}$ \\
\hline Bal. & 4.5 & 20 & 9.2 & 0.46
\end{tabular}

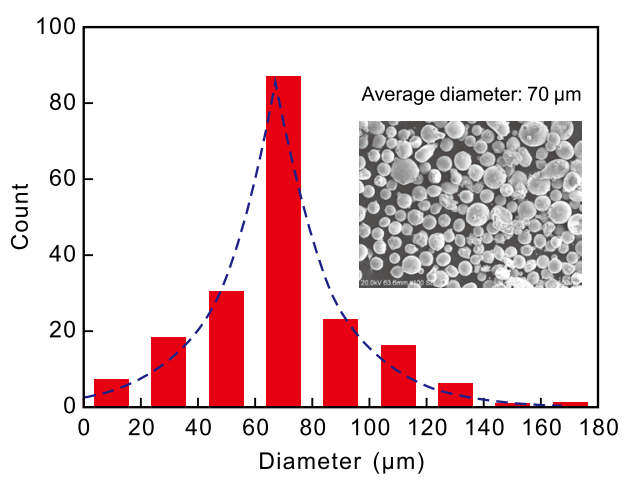

Fig. 1: Morphology and size distribution of alloy powder

The as-deposited sample was fabricated by a coaxial LMD system shown in Fig. 2(a) with laser power of 2,000 W and laser scanning speed of $25 \mathrm{~mm} \cdot \mathrm{s}^{-1}$. The elevation height is $2 \mathrm{~mm}$ each time and the overlap rate is greater than $30 \%$. LMD was performed with a continuous $\mathrm{CO}_{2}$ laser heat source (the beam diameter is about $0.9 \mathrm{~mm}$ ). The substrate samples were cut from DZ40M, a directional solidification superalloy in solid solution heat treatment condition. Processing strategy, and the as-deposited sample and tensile specimen diagram are demonstrated in Figs. 2(b)-(d), respectively. (a)

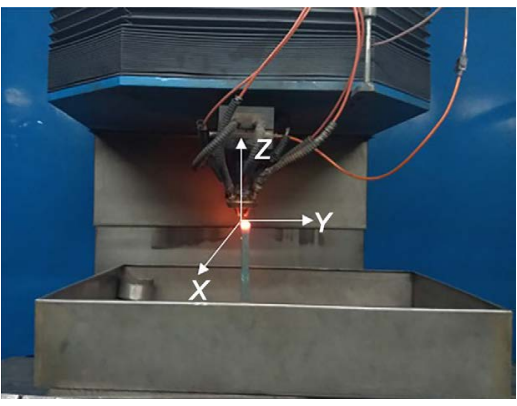

(c)

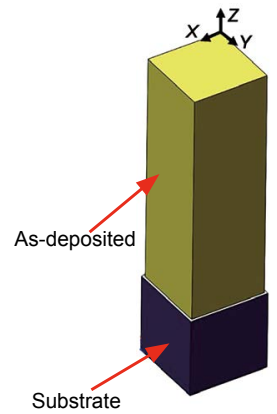

(b)
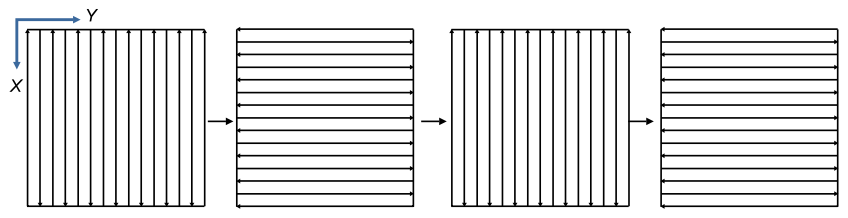

Cross direction raster scanning:

As denoted by the diagram, samples were scanned by the laser beam alternatively along positive and negative of $X$ direction, then continuing the same operation by rotating an angel of $90^{\circ}$ (that is, along positive and negative of $Y$ direction). After identical double cycles, the sample was elevated one appropriate distance along $Z$ direction, then the next operation began the same way. Thus, layer by layer, the specimen of desire size can be ultimately obtained.

(d)

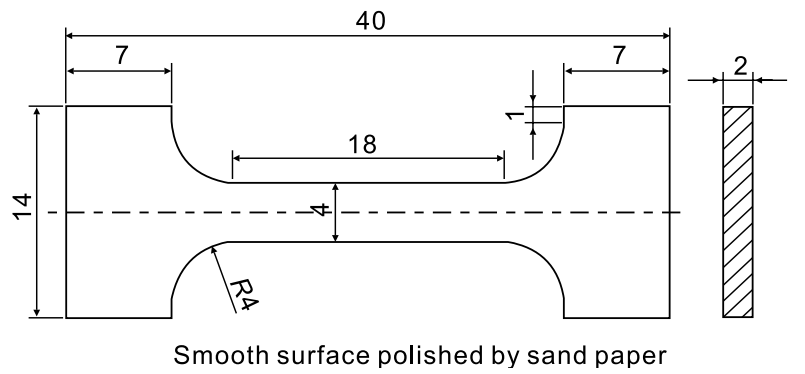

Fig. 2: Coaxial LMD system (a), processing strategy (b), as-deposited sample (c) and tensile specimen diagram (d) 
For comparison, the casting ingots have the same composition as AM raw powder. The ingot was made as follows: first, melting the master alloy in vacuum induction melting (VIM) furnace, then holding at $1,500{ }^{\circ} \mathrm{C}$ for $5 \mathrm{~min}$, after that pouring the molten alloy into a ceramic shell mold with outer diameter of $80 \mathrm{~mm}$ and inner diameter of $30 \mathrm{~mm}$ (hollow bar), then air cooling. The length of the bar was more than $300 \mathrm{~mm}$.

\subsection{Thermo-Calc simulation}

The solidification sequence was calculated by Thermo-Calc software with TTNI8 database. The simulation was carried out under two conditions. One is the thermo-dynamic equilibrium condition, where the calculation was programed from $1,400{ }^{\circ} \mathrm{C}$ to $400{ }^{\circ} \mathrm{C}$ by a step of $10{ }^{\circ} \mathrm{C}$. The other is calculated according to Scheil model, which is a kind of non-equilibrium condition based on the Scheil equation ${ }^{[21]}$ :

$$
\begin{gathered}
C_{\mathrm{L}}^{*}=C_{0}\left(1-f_{\mathrm{S}}\right)^{\left(k_{0}-1\right)} \\
C_{\mathrm{S}}^{*}=k_{0} C_{0} f_{\mathrm{L}}^{\left(k_{0}-1\right)}
\end{gathered}
$$

where $C_{\mathrm{L}}^{*}$ and $C_{\mathrm{S}}^{*}$ are concentration of liquid and solid at liquid/ solid interface respectively, $C_{0}$ is the original concentration of the alloy, $f_{\mathrm{S}}$ and $f_{\mathrm{L}}$ are the solid volume fraction and liquid volume fraction, respectively, $k_{0}$ is the equilibrium solute partition coefficient, $k_{0}=C_{\mathrm{S}}^{(\mathrm{eq})} / C_{\mathrm{L}}^{(\mathrm{eq})}, C_{\mathrm{L}}^{(\mathrm{eq})}$ and $C_{\mathrm{S}}^{(\mathrm{eq})}$ are concentration of liquid and solid under equilibrium condition, respectively. This calculation proceeded every $1^{\circ} \mathrm{C}$ from $1,400{ }^{\circ} \mathrm{C}$ to $400{ }^{\circ} \mathrm{C}$ until complete solidification ${ }^{[19]}$.

\subsection{Material measuring and characterization}

DSC tests were carried out on a Netzsch STA409 tester to obtain the transformation temperature of the main phases. The sample adopted in DSC testing is a superalloy powder produced by gas atomization. To minimize the effect of oxidation, all experiments were performed in crucibles of high-purity $\mathrm{Al}_{2} \mathrm{O}_{3}$ surrounded by dynamic atmosphere with high purity Ar. The samples were heated and cooled according to the rules illustrated in Fig. 3. Finally, the liquidus was estimated from cooling curve, and the solidus was estimated from heating curve according to general principles ${ }^{[19]}$.

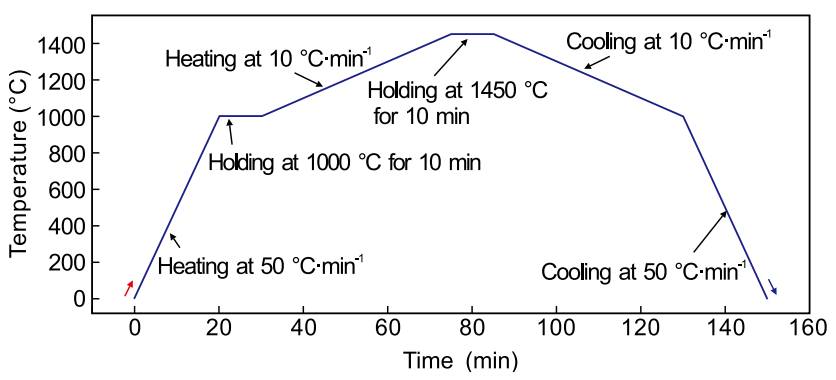

Fig. 3: Heating and cooling rules in DSC testing

SEM (INSPECT F50) and TEM (JEOL 2100) were both used for microstructure observation. SEM specimens were etched with reagent mixed by $100 \mathrm{~mL} \mathrm{HCl}+100 \mathrm{~mL} \mathrm{H}_{2} \mathrm{O}+5 \mathrm{~mL}$ $\mathrm{H}_{2} \mathrm{SO}_{4}+20 \mathrm{~g} \mathrm{CuSO}_{4}$. TEM observations were performed at
$200 \mathrm{kV}$ accelerating potential. Thin foils for TEM observation were cut from the as-deposited sample, which were ground to the thickness of about $50 \mu \mathrm{m}$ then electro-polished in a solution of $90 \mathrm{~mL}$ ethanol and $10 \mathrm{~mL}$ perchloric at $-17{ }^{\circ} \mathrm{C}$ and $24 \mathrm{~V}$. Image-Pro Plus 6.0 (IPP) was used to analyze phase fraction and particle morphology. The size of the precipitation was weighed by the average values of the distinct $\gamma^{\prime}$ particles. At least 5-10 typical areas were selected for each sample in the statistical analysis. X-ray diffraction (XRD, D8 Discover, Bruker, Germany) with $\mathrm{Cu} \mathrm{K \alpha}$ radiation was used to identify the phase constitution. The specimen for XRD was cut perpendicular to the deposition direction.

The tensile specimens were cut from the as-deposited and as-cast samples by electro-discharge machining according to Fig. 2(d), and ground manually with SiC sandpaper (from \#400 to \#1,000) until the surface was smooth. The asdeposited specimen was cut along the deposition direction, and the as-cast specimen was cut from the middle part of the ingot. Tensile testing was performed on a SANS-CMT5205 testing machine at room temperature according to GBT228.12010 at a strain rate of $0.2 \mathrm{~mm} \cdot \mathrm{min}^{-1}$. Three parallel tensile specimens were tested for as-deposited and two for as-cast. The tensile properties were obtained from stress-strain curves, including yield strength (YS, $0.2 \%$ offset), ultimate tensile strength (UTS), and elongation. Tensile fracture surface was also characterized by SEM.

\subsection{Heat treatment}

The as-deposited samples were aged at $750{ }^{\circ} \mathrm{C}$ for $1,000 \mathrm{~h}$, and subjected to $870{ }^{\circ} \mathrm{C}$ for $16 \mathrm{~h}$, respectively, to investigate the effect of thermal history on phase formation.

\section{Results and analysis}

\subsection{Phases and their transformation in newly developed Ni-based superalloy}

\subsubsection{Thermodynamic calculations and DSC analysis}

Figure 4 presents the calculated results under thermodynamic equilibrium conditions by Thermo-Calc. This diagram indicates that the main phases of this newly developed alloy are $\gamma$ and $\gamma^{\prime}$. The matrix is $\gamma$ and it starts solidifying at $1,353.5^{\circ} \mathrm{C}$, which is the liquidus temperature. Solidification ends at $1,272.2{ }^{\circ} \mathrm{C}$ where the liquid fraction is zero [Fig. 4(c)]. After the solidification of the $\gamma, \gamma^{\prime}$ phase begins to precipitate at $1,096.3{ }^{\circ} \mathrm{C}$ from the matrix $\gamma$. With decreasing temperature, the $\gamma^{\prime}$ fraction increases [Fig. 4(a)]. Other phases, such as $\mathrm{MC}$ carbide, $\mu$ phase, $\mathrm{M}_{23} \mathrm{C}_{6}$ carbide and $\mathrm{Ni}_{5} \mathrm{M}$ precipitate in the cooling process at $1,284{ }^{\circ} \mathrm{C}, 765^{\circ} \mathrm{C}, 582{ }^{\circ} \mathrm{C}$ and $580.5^{\circ} \mathrm{C}$, respectively. Among them, only $\mathrm{MC}$ can precipitate directly from liquid. The solidification temperature scope from liquidus to solidus is from $1,353.5^{\circ} \mathrm{C}$ to $1,272.2^{\circ} \mathrm{C}$.

The Scheil model, which assumes no solute back diffusion in the solid and perfect mixing in the liquid, is another method used to estimate the solidification sequence and the solid fraction as a function of temperature. As shown in Fig. 5, $\gamma$ starts solidifying at $1,353.02{ }^{\circ} \mathrm{C}$, which is the liquidus temperature. 

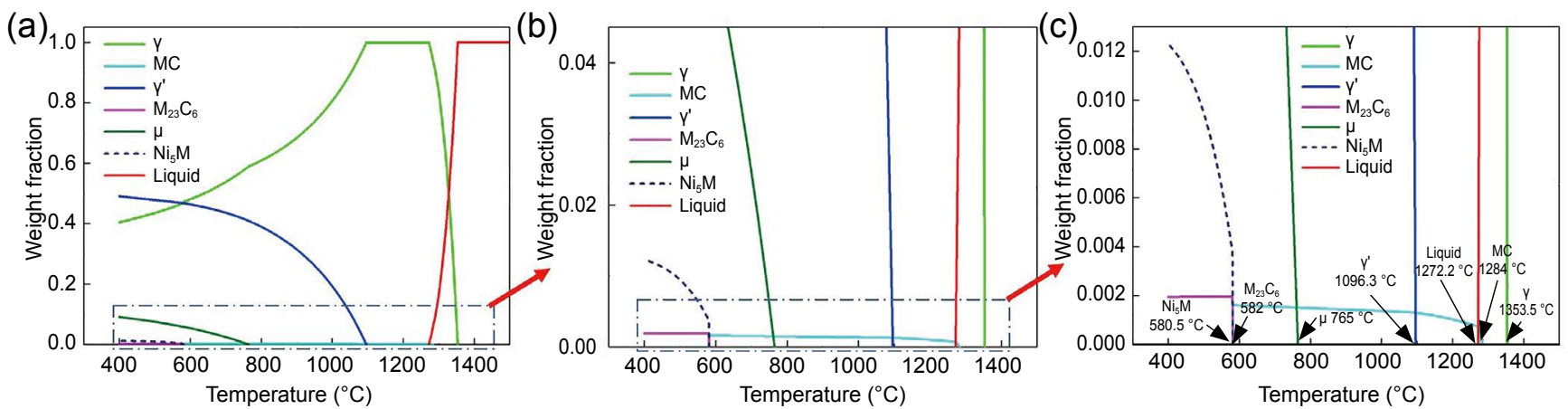

Fig. 4: Equilibrium phases diagram (temperature versus weight fractions) of superalloy calculated by Thermo-Calc: (a) general view; (b) region of interest enlarged from (a); (c) region of interest enlarged from (b)

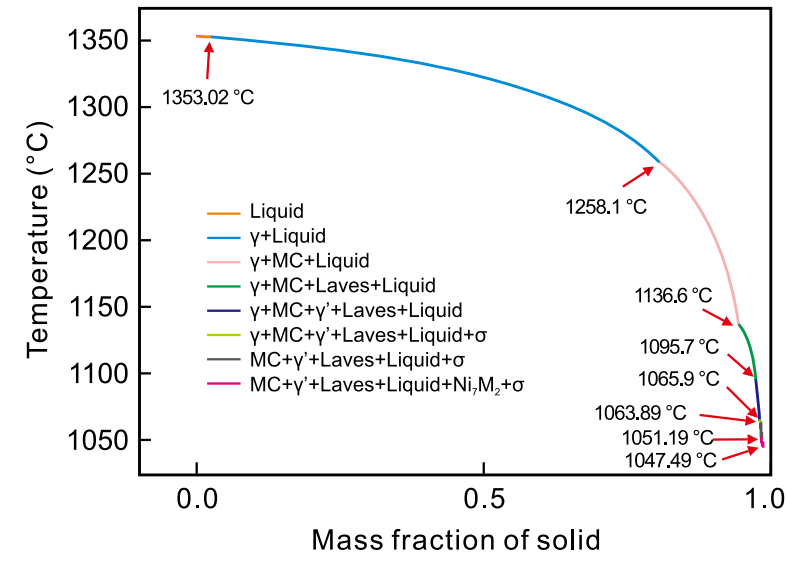

Fig. 5: Solidification sequence calculated by Scheil model

The solidification ends at $1,047.49{ }^{\circ} \mathrm{C}$ where the liquid fraction is zero. Other phases, such as MC carbide, Laves phase, $\gamma^{\prime}, \sigma$ and $\mathrm{Ni}_{7} \mathrm{M}_{2}$ precipitate at $1,258.1{ }^{\circ} \mathrm{C}, 1,136.6{ }^{\circ} \mathrm{C}, 1,095.7{ }^{\circ} \mathrm{C}$, $1,065.9{ }^{\circ} \mathrm{C}$ and $1,051.19{ }^{\circ} \mathrm{C}$, respectively. It is noted that the liquid has not disappeared when they begin to precipitate. The solidification temperature's scope from liquidus to solidus is from $1,353.02{ }^{\circ} \mathrm{C}$ to $1,047.49{ }^{\circ} \mathrm{C}$.
Figure 6 presents the DSC curves of the superalloy powder during heating and cooling processes. Some important temperature points can be acquired, such as the solidus temperature is $1,288^{\circ} \mathrm{C}$ (obtained at the point by extrapolating baseline in the heating curve until it intersects the tangent of the maximum curve slope), and the liquidus temperature is $1,335^{\circ} \mathrm{C}$ (the first sharp inflection point in the cooling curve).

Considering the temperature scope from $1,450{ }^{\circ} \mathrm{C}$ to $1,000{ }^{\circ} \mathrm{C}$ in Fig. $6(\mathrm{~b})$, four points $\left(1,335^{\circ} \mathrm{C}, 1,212{ }^{\circ} \mathrm{C}, 1,128{ }^{\circ} \mathrm{C}, 1,035^{\circ} \mathrm{C}\right)$ might be the phase transformation critical temperature, comparing with the solidification sequence calculated by the Scheil model in Fig. 5 (illustrated as $1,353.02{ }^{\circ} \mathrm{C}, 1,258.1{ }^{\circ} \mathrm{C}$, $1,136.6{ }^{\circ} \mathrm{C}, 1,095.7{ }^{\circ} \mathrm{C}$ ), the corresponding phases are inferred to be $\gamma$, MC carbides, Laves and $\gamma^{\prime}$, respectively. The detail phase transformation temperatures are listed in Table 2. Their difference values $\left(-60.7{ }^{\circ} \mathrm{C},-8.6{ }^{\circ} \mathrm{C},-46.1^{\circ} \mathrm{C},-18.02{ }^{\circ} \mathrm{C}\right)$ are actually supercooling since the Scheil model uses a local equilibrium condition. In addition, the peak point in Fig. 6(b), $1,322{ }^{\circ} \mathrm{C}$, is corresponding to the formation of $\gamma$ dendrite at the greatest growth rate; while $1,272{ }^{\circ} \mathrm{C}$, could be the last stage of the transition.
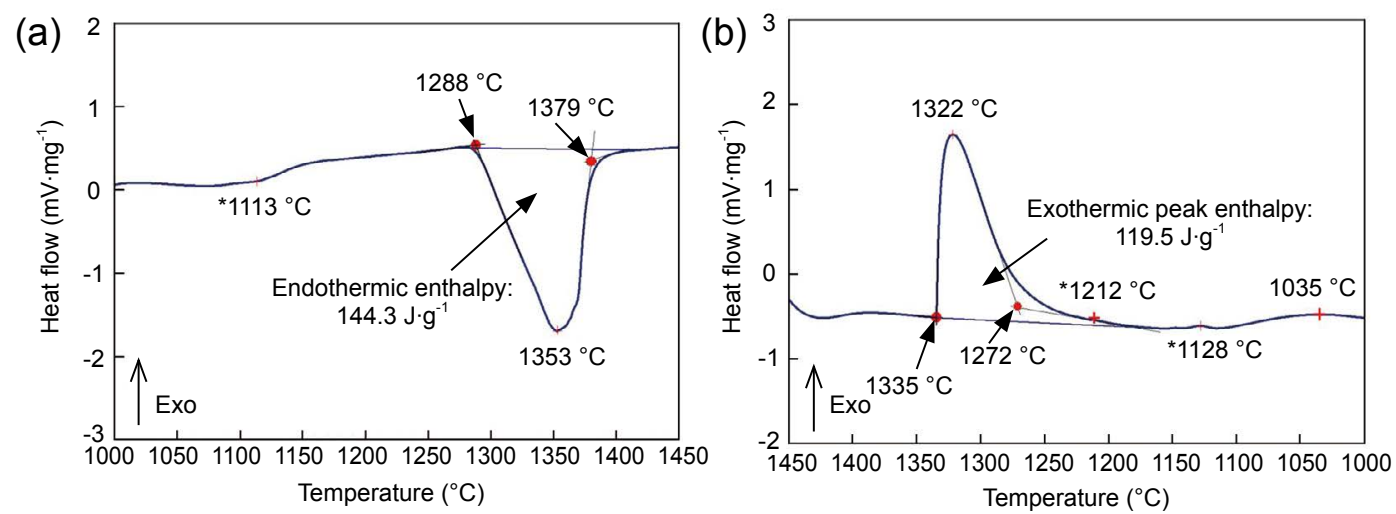

Fig. 6: DSC curves of superalloy powder under heating process (a) and cooling process (b)

Following the same principle, from the heating curve, the critical temperature of $\gamma^{\prime}$ begins to dissolve is $1,113{ }^{\circ} \mathrm{C}$, and the melting of the $\gamma$ matrix is $1,288{ }^{\circ} \mathrm{C}$. Furthermore, the peak point in Fig. 6(a), $1,353{ }^{\circ} \mathrm{C}$, is corresponding to the formation of liquid at the greatest melting rate; while $1,379^{\circ} \mathrm{C}$ could be the last stage of the transition where the solid fraction is close to zero. It is noted that there is no obvious transition temperature of MC and Laves, which might be attributed to transition kinetics reasons or their small mass fraction.

The detailed information of solidification calculation and DSC measurement is summarized and listed in Table 2 (for cooling conditions) and Table 3 (for heating conditions). The corresponding phase transformation temperatures obtained from the cooling curve are lower than those from equilibrium 
Table 2: Major phase transformation temperatures obtained from solidification calculation and DSC measurement $\left({ }^{\circ} \mathrm{C}\right)$ under cooling conditions

$\begin{array}{cccccc} & & T_{\mathrm{V} \rightarrow \mathrm{Y}^{\prime}} / T_{\mathrm{L} \rightarrow \mathrm{Y}^{\prime}} & T_{\mathrm{L} \rightarrow \mathrm{Laves}} & T_{\mathrm{L} \rightarrow \mathrm{MC}} & T_{\mathrm{L} \rightarrow \mathrm{Y}} \\ \text { Equilibrium model } & \text { Cooling } & 1,096.3 & - & 1,284 & 1,353.5 \\ \text { Scheil model } & \text { Cooling } & 1,095.7 & 1,136.6 & 1,258.1 & 1,353.02 \\ & \text { Cooling } & 1,035 & 1,128 & 1,212 & 1,335 \\ \text { DSC } & \text { Supercooling } & -60.7 & -8.6 & -46.1 & -18.02\end{array}$

Table 3: Major phase transformation temperatures obtained from solidification calculation and DSC measurement $\left({ }^{\circ} \mathrm{C}\right)$ under heating conditions

\begin{tabular}{cccccc} 
& & $T_{\mathrm{V}^{\prime} \rightarrow \mathrm{V}}$ & $T_{\mathrm{V} \rightarrow \mathrm{L}}$ & $T_{\mathrm{MC} \rightarrow \mathrm{L}}$ & $T_{\mathrm{L} \rightarrow 1}$ \\
Equilibrium model & Heating & $1,096.3$ & $1,272.7$ & 1,284 & $1,353.5$ \\
\cline { 2 - 4 } & Heating & 1,113 & 1,288 & - & 1,379 \\
& Superheating & 16.7 & 15.3 & - & 25.5
\end{tabular}

calculations, their differences are termed as supercooling degree. Similarly, the corresponding phase transformation temperatures obtained from the heating curve are higher than those from equilibrium calculations, their differences are termed as superheating degree. Thermodynamically, both supercooling and superheating provide driving force for phase transition. (Note: In Table 2, supercooling was obtained by subtracting the phase transformation temperature of Scheil model from that of the DSC, while in Table 3, superheating was obtained by subtracting the value of equilibrium from the DSC. The calculation is based on the assumption that the corresponding phase has the same chemical composition).

In summary, the phase transformation temperatures calculated by Thermo-Calc equilibrium model deviate from that of Scheil model to some extent. Results of DSC analysis are more closely aligned with the Scheil model assumption. Liquidus predicted by the Thermo-Calc equilibrium model and Scheil model is almost the same, however the DSC plots show that the transformation temperature from liquid to solid is $1,335^{\circ} \mathrm{C}$, their differences should be the supercooling.

\subsubsection{XRD and TEM analysis}

Figure 7(a) presents the X-ray diffraction spectrum of the asdeposited sample. There is only a peak at $2 \theta=50.98^{\circ}$, which indicates that only the diffraction of the (200) crystallographic plane of the $\gamma / \gamma^{\prime}$ phase is detected. Directly by this XRD spectrum, it is difficult to differentiate $\gamma$ and $\gamma^{\prime}$ phase in the superalloy because the lattice parameters of them are approximately equal. The strong peak at $50.98^{\circ}$ also indicates that the as-deposited sample has strong textile structure along the (200) crystallographic plane, the normal direction of which is parallel to the build direction of LMD. Peaks for other crystallography planes are too weak to be observed (if they exist) and can be ignored here. In addition, the volume fraction of other phases such as MC carbides, Laves, etc., are too low to be visible in XRD spectrum.

The electron diffraction pattern of $\gamma / \gamma^{\prime}$ was also obtained via TEM, as shown in Fig. 7(b). Based on the results, the matrix is $\gamma$ and the precipitation is $\gamma^{\prime}$. Similar to the data reported in the Refs. [22, 23], the crystal structure of $\gamma$ and $\gamma^{\prime}$ are FCC and L12, respectively. The orientation relationship between the $\gamma$ and $\gamma^{\prime}$ phase can be inferred as follows:

$$
\begin{aligned}
& \{100\} \gamma / /\{100\} \gamma^{\prime} \\
& <010>\gamma / /<010>\gamma^{\prime}
\end{aligned}
$$

The $\gamma^{\prime}$ remains coherent with $\gamma$ at $\gamma / \gamma^{\prime}$ interface and $\gamma^{\prime}$ particles are embedded in $\gamma$ matrix. In summary, both XRD and TEM results show that the basic phases of the as-deposited alloy are coherent $\gamma / \gamma^{\prime}$ (Fig. 7). The build direction of LMD is along the normal (200) crystallographic plane.
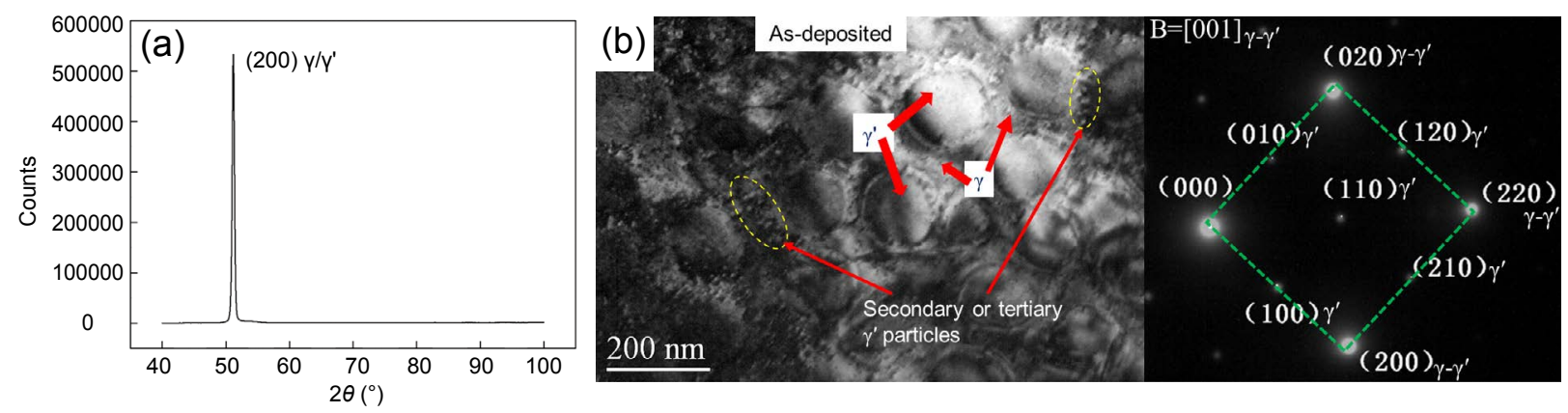

Fig. 7: Basic phases of as-deposited alloy and crystallography orientation: (a) XRD spectrum of as-deposited samples (measured surface normal to the deposition direction); (b) TEM bright field image and electron diffraction of as-deposited alloy 


\subsection{Microstructure analysis}

\subsubsection{Microstructure of as-deposited alloy}

The microstructure of the as-deposited alloy prepared by LMD is shown in Fig. 8, where deposition direction is denoted by Axis Z. From Fig. 8, it can be seen that this sample has a typical cellular dendrite. In the direction perpendicular to the deposition direction, dendrite and interdendritic regions are arrayed like chess board, as seen in Fig. 8(a). In the direction parallel to the deposition, fine parallel dendrites are clearly visible, as shown in Fig. 8(b). During LMD, the dendrites epitaxially grow from the substrate. The interdendritic regions are formed during the last stage of solidification. Laves phase and $\mathrm{MC}$ carbides are commonly observed at the interdendritic regions due to microsegregation of solute elements by SEM. By statistical analysis from Fig. 8(a), the average primary dendrite arm space (PDAS) is about $30-45 \mu \mathrm{m}$. Almost no secondary arm is observed in Fig. 8(b). There are $\gamma^{\prime}$ particles precipitated in both dendrite and interdendritic regions. Their average volume fraction of $\gamma^{\prime}$ is about $30 \%$ according to experiment results. Precipitation of MC carbides and Laves phase usually have larger size (about several microns in average diameter), but their volume fractions are less than $1 \%$ in all. According to theoretical calculation, Laves phase is about $0.7 \%$ in volume fraction, while $\mathrm{MC}$ carbides only $0.1 \%$ or so. Furthermore, micro-segregation is found by EPMA, the element map is shown in Fig. 8(c), to be brief, only $\mathrm{Al}$ and $\mathrm{Nb}$ are displayed, no macro-segregation is present.

The $\gamma^{\prime}$ phase is the main strengthening phase in Ni-based superalloys and it usually coherently precipitates from the supersaturated matrix during the solidification process. When the laser beam periodically scans in the processing, $\gamma^{\prime}$ precipitate will nucleate and grow up from the heat-affected zone (HAZ) of supersaturated $\gamma$ matrix. As shown in Fig. 8, the typical morphology of $\gamma^{\prime}$ particles is near sphere shape both in the dendritic and interdendritic regions. The average size of $\gamma^{\prime}$ particles is $100-150 \mathrm{~nm}$ and usually the interdendritic regions have coarser particles. TEM gives more detailed information about $\gamma^{\prime}$ phase as shown in Fig. 7(b). There are still some tiny particles in the $\gamma / \gamma^{\prime}$ interface which are often termed as secondary or tertiary $\gamma^{\prime}$ particles, and precipitate due to the HAZ effects during laser processing.

(b)
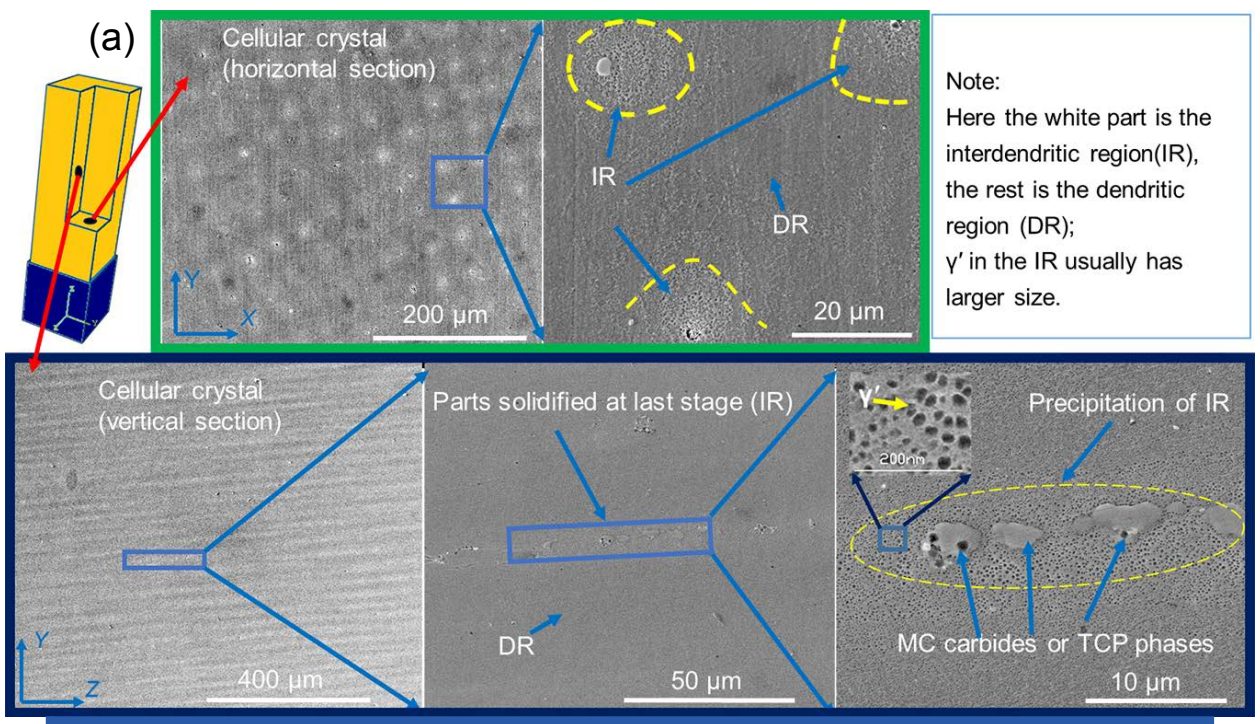

(c)

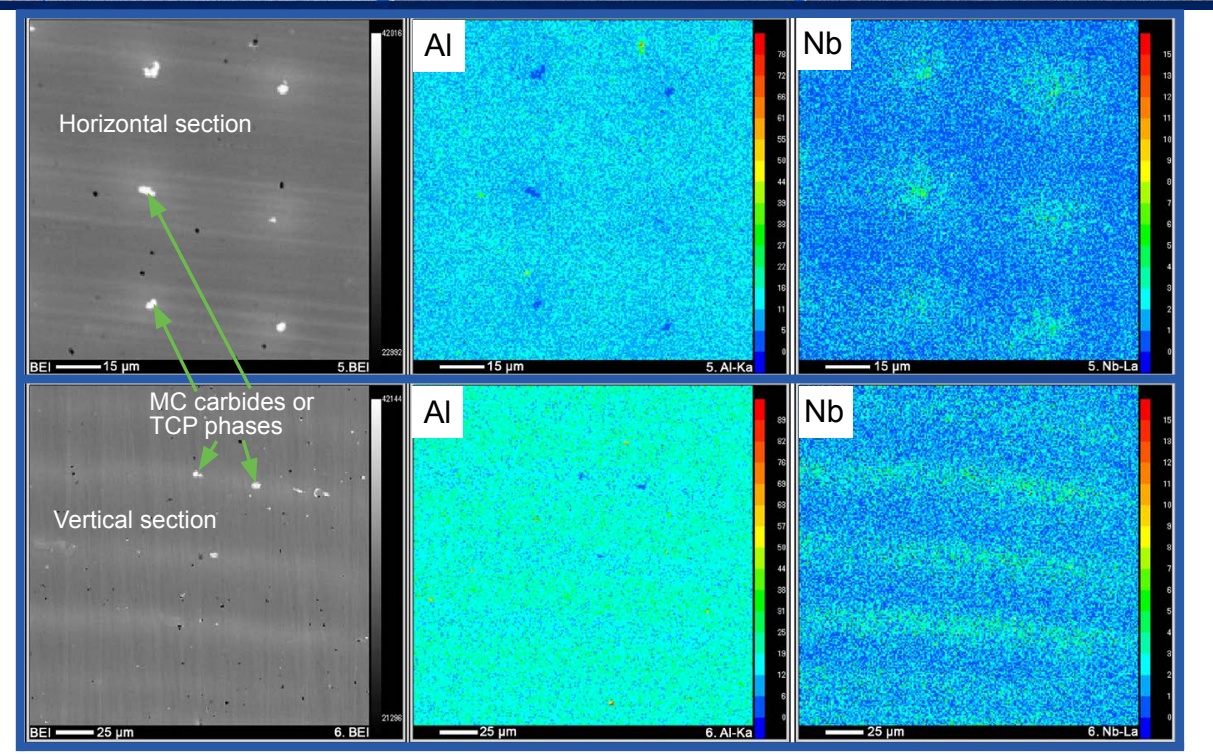

Fig. 8: Microstructure of as-deposited alloy and typical morphologies of precipitates: (a) horizontal section;

(b) vertical section; (c) element map of alloy 


\subsubsection{Microstructure of as-cast alloy}

The microstructure of the as-cast alloy is shown in Fig. 9. It is a typical equiaxed dendrite. There is a secondary and even ternary dendrite arm observed in the as-cast microstructure. Its typical PDAS is $300-500 \mu \mathrm{m}$, much larger than that of the as-deposited. The arm space of its secondary dendrite is about $100-150 \mu \mathrm{m}$. The volume fraction of $\gamma^{\prime}$ particles in the dendrite is about $34.9 \%$ while that is around $41.1 \%$ in the interdendrite. Similar to the as-deposited alloy, MC carbides and Laves precipitates, as well as $\gamma / \gamma^{\prime}$ eutectics appear mainly in the interdendritic regions. Laves looks like networks, and $\gamma / \gamma^{\prime}$ eutectics exhibit sunflowers shape and have a larger size scope [Figs. 9(b) and 13(b)] comparing with that of the as-deposited one. Laves precipitates are very bright in the back scattering electronic images which demonstrate the phases containing high atomic number elements. In addition, those precipitates enrich with high atomic number refractory elements are often observed in the grain boundary too, as shown in Fig. 9(c), which is due to macro segregation in the boundary regions and the size more than $100 \mu \mathrm{m}$ as well.

As shown in Fig. 9(a), the typical morphology of $\gamma^{\prime}$ particles shows near cubic or butterfly shape in the interdendritic regions and near sphere shape in the dendritic regions. The average sizes of $\gamma^{\prime}$ particles in them are $315 \mathrm{~nm}$ and $208 \mathrm{~nm}$ respectively, larger than that of the as-deposited as well. The morphological development of $\gamma^{\prime}$ precipitates occurs in the sequence of spheres, cubes, octets with concave features (like butterfly), and eventually solid-state dendrites according to the outer conditions ${ }^{[22,24]}$, including solution temperature, soaking time, and cooling rate, etc. Of note in Fig. 9, $\gamma^{\prime}$ particles of butterfly shape in the interdendritic regions develop better than those of the dendritic regions which have near-sphere shape.

(b)

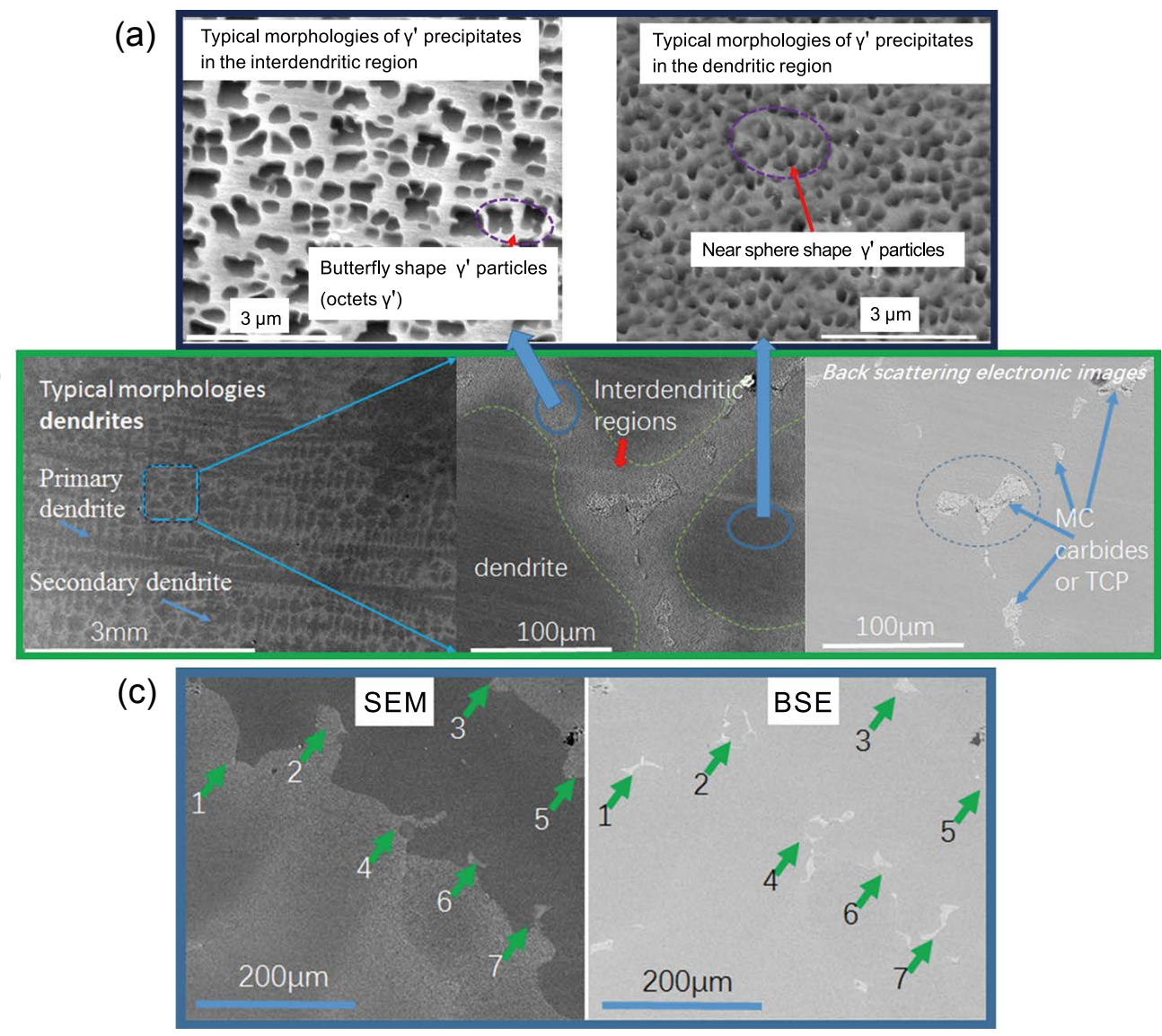

Fig. 9: Microstructure of as-cast alloy: (a) morphology of $\mathrm{Y}^{\prime}$ particles; (b) morphology of dendrite; (c) grain boundary precipitates

\subsection{Mechanical properties}

\subsubsection{Mechanical properties and deformation microstructure}

The tensile engineering stress-strain curves of the as-cast and the as-deposited samples at room temperature are displayed in Fig. 10(a). The as-deposited specimen shows obviously better ultimate tensile strength (UTS, 1,085.7 $\pm 51.7 \mathrm{MPa}$ ), yield strength (YS, $697 \pm 19.5 \mathrm{MPa}$ ) and elongation $(25.8 \% \pm 2.2 \%)$ than that of the as-cast, as shown in Table 4.

The exterior appearance of the tensile specimen is also denoted in the insets of Fig. 10(a). For the as-deposited specimen, the angle between the normal orientations of fracture surface and the stress axis is about $45^{\circ}$. According to the Schmid law, it is inferred that the detach shear fracture is along with slip system $\{111\}<110>$. While for the ascast specimen, which is polycrystalline structure, its fracture surface is approximately perpendicular to applied stress.

Typical deformation microstructure of the as-deposited specimen is observed by TEM, as shown in Fig. 10(b). The specimen is cut from near fracture region after tensile testing. TEM micrograph presents highly planar, faulted structures 
(a)

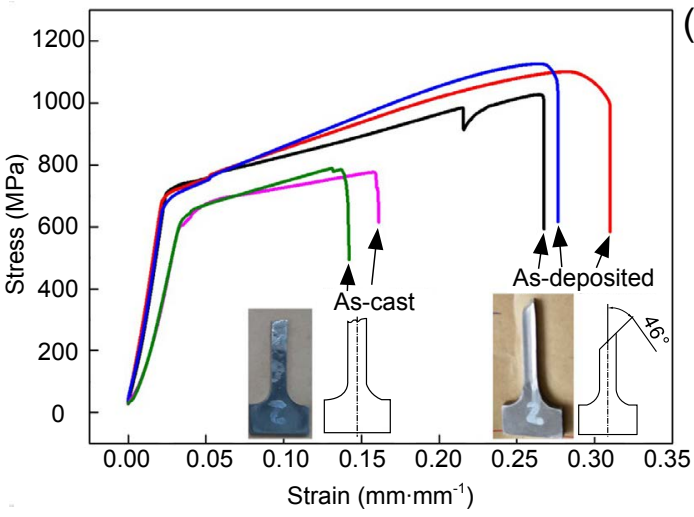

(b)

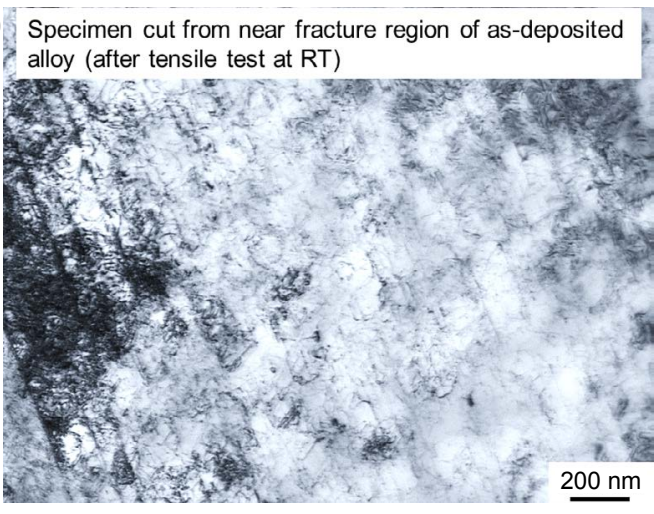

Fig. 10: Comparison between as-cast and as-deposited alloy tensile stress-strain curves during tensile tests at room temperature (a), TEM images of deformation microstructures of as-deposited alloy (b)

Table 4: Mechanical properties of alloy

\begin{tabular}{cccc|} 
Sample state & UTS (MPa) & YS (MPa) & $\begin{array}{c}\text { Elongation } \\
(\%)\end{array}$ \\
\hline As-deposited & $1,085.7 \pm 51.7$ & $697 \pm 19.5$ & $25.8 \pm 2.2$ \\
As-cast & $782.7 \pm 8.6$ & $616.7 \pm 16.5$ & $12.6 \pm 1.2$
\end{tabular}

that shear both the $\gamma$ matrix and the $\gamma^{\prime}$ particles, most of which are continuous and seem to span across the entire zone. The faulted structures could be slip bands, stacking fault (CSF) or microtwins. Parallel stripes occurring in the deformation microstructure are due to cooperative shearing being on adjacent $\{111\}$ glide planes. The detailed deformation mechanism is very important but is omitted here because it is beyond the scope of this article.

\subsubsection{Morphology of tensile fracture surface}

The fractured surfaces of the as-cast and the as-deposited specimens were examined to correlate the tensile characteristics with microstructures. The two kinds of specimens have entirely different fracture features as shown in Figs. 11 and 12. For the as-deposited specimen, the typical dimple feature can be found on the fracture surfaces with a localized ductile-brittle mixedmode behavior (Fig. 11). The as-cast one exhibits a clear brittle fracture. The transgranular cleavage patterns are found on the surface of the fracture (Fig. 12).

Figure 11 displays the fracture surfaces of the asdeposited alloy. The total surface can be divided into several regions indicated by A, B, C, D, and E. According to their characteristic, the process of the fracture can be inferred as follows. Slip system $<110>\{111\}$ starts when critical resolved shear stress (CRSS) is achieved which produces shear deformation. Original crack occurs at Region A (as denoted by arrows) and propagates through Region $\mathrm{B}$ until hindered by precipitates such as MC or crystal defects like dislocations. The blocked crack transfers from original crystal slip plane to another plane which is easier to crack, and thus stages formed, as shown in Region B of Fig. 11. Arrow F denotes such precipitates (probably crisp phase) at transition region of steps. Regions $\mathrm{C}$ and $\mathrm{D}$ are propagated zones of cracks which display a relatively larger flat planar zone, and the profiles of chess board dendrites section are easily observed here. In magnifying the local area of the surface, a great number of tearing ridges, dimples, and column holes are observed. The holes deform with almost the same direction and there are many parallel slip bands in the holes. Finally, the instant rupture area occurs at Region $\mathrm{E}$ with shear lips produced on the fracture surface.

Figure 12 displays the fracture surface of the as-cast alloy after tensile testing. The as-cast alloy exhibits a clear brittle fracture with a multiple cracks propagate characteristic. Evident large cleavage plane and small terraces are clearly observed (denoted by Arrow C). Furthermore, the surface of the part indicated by Arrow A is smooth, which is supposed to be the liquid film formed in the last solidification stage of casting. The brittle fracture of the part indicated by Arrow B is obvious, which is supposed to be the brittle eutectic formed during the final solidification. These are the factors that reduce the ductility of the alloy and promote the fracture of the alloy.

From mechanism analysing of the tensile fracture above, it is obvious that the as-deposited specimen is more difficult to fracture than that of the as-cast. The former endures more deformation in the linearly hardening region as shown in Fig. 10(a). Therefore, its ultimate tensile stress is greater and its elongation is almost twice the latter.

\section{Discussion}

The simulation and experimental results show that the alloy produced by LMD and casting has the same basic phase $\gamma / \gamma^{\prime}$, but the morphology, size and volumn fraction of $\gamma^{\prime}$ are distinctly different, so as the secondary phases. Furthermore, the different processes lead to different solidification dendrite. To control the microstructure and properties of the alloy, it is necessary to further understand the formation mechanism and principle of these differences.

\subsection{Morphology and size of solidification dendrite}

Researchers ${ }^{[25]}$ have found that solidification structure is dependent on two most important parameters: $R$ (the local solidification growth rate), and $G$ (the temperature gradient 


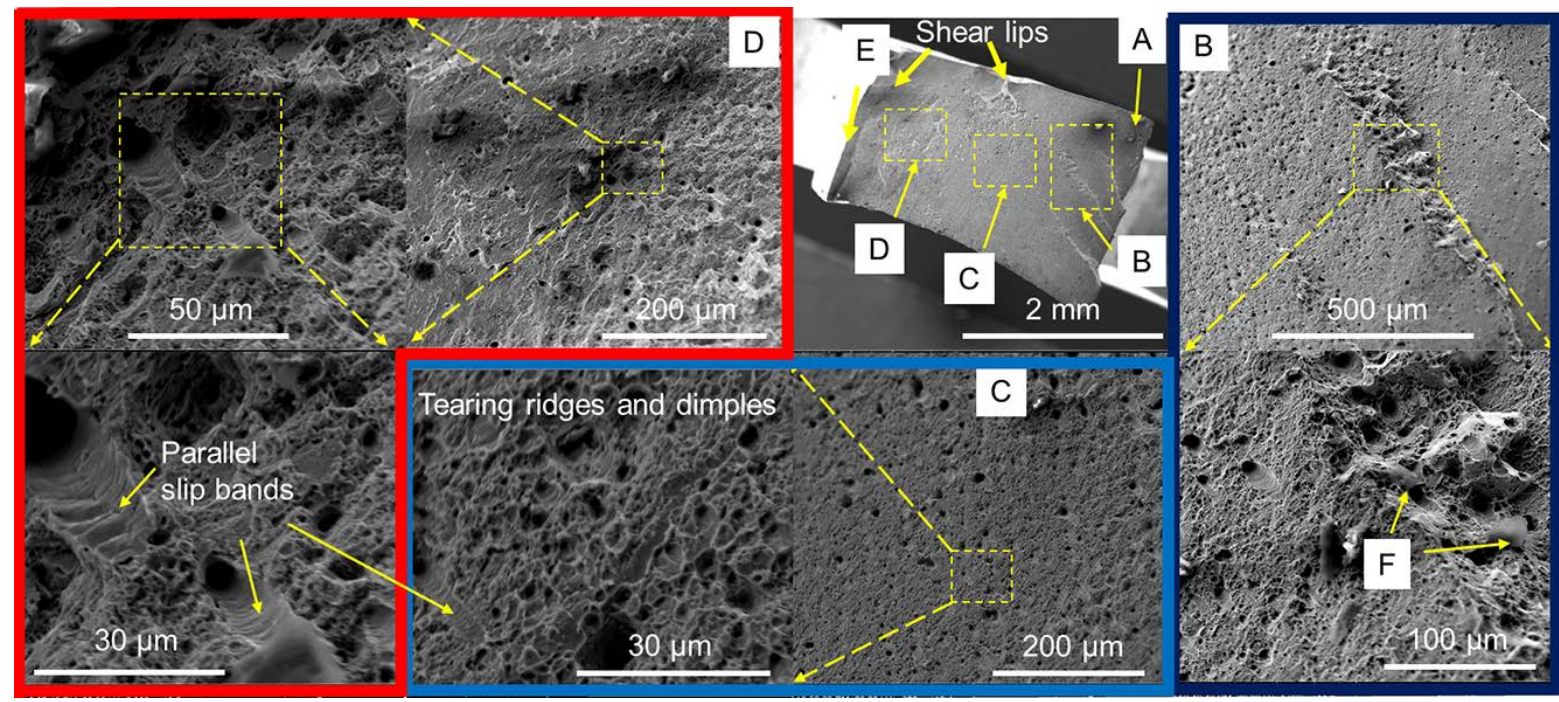

Fig. 11: Fracture surfaces of as-deposited alloy after tensile testing at room temperature

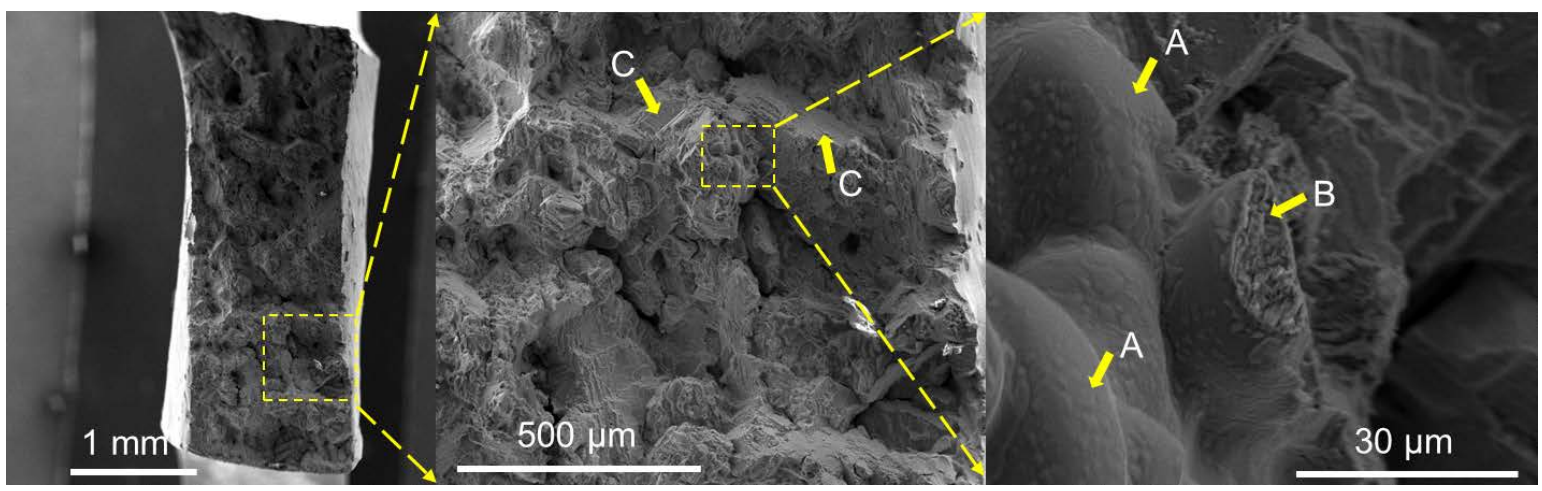

Fig. 12: Fracture surfaces of as-cast alloy after tensile testing at room temperature

at the solid-liquid interface). The ratio $G / R$ determines the mode of solidification, therefore it affects the morphology of the solidification structure, while the $G R$ governs the scale of the solidification microstructure. The solidification map can also be found in Ref. [25]. Researchers often use PDAS ${ }^{[26-29]}$ to quantitatively describe the size of dendrite structure, and its expression is often abbreviated as:

$$
\lambda_{1}=N G^{-a} V^{-b}(0<a, b<1)
$$

where $\lambda_{1}$ is the PDAS, $G$ and $V$ are the temperature gradient and the dendritic growth velocity, respectively, $a, b$, and $N$ are material-dependent parameters. Generally, $a=0.5$ and $b=0.25$. For as-deposited and as-cast structures, PDAS is 30 $45 \mu \mathrm{m}$ and $300-500 \mu \mathrm{m}$, respectively, which is caused by the difference of temperature gradient and solidification rate between them.

In this research, both the temperature gradient $G$ and dendritic growth velocity $V$ are larger in value during LMD, and very small cellular dendrite is the dominant morphology (as shown in Fig. 8). The size of the eutectic structure and precipitates are relatively small because there is limited space left during the last stage of solidification. Moreover, for the casting process, $G$ and $V$ are far less than that of LMD. There is almost no solute trapping phenomenon that can occur in $\mathrm{LMD}$, and the element segregation is relatively serious. Coarse equiaxed dendrite is the dominant morphology, as shown in Fig. 9(a). Either dendrite or eutectic is coarser [Fig. 9(b)], which is due to the residual liquid having enough space and time to form the eutectic products during the last stage of solidification.

\subsection{Phase formation in alloys}

The solidification and solid phase transformation in alloys follow the principles of thermodynamics and kinetics. For multicomponent alloys, it is impossible to achieve the ideal equilibrium conditions during solidification, and the atomic rearrangement and element segregation will inevitably occur. The final dendrites and precipitates are determined by two factors: the actual solute conditions (solute redistribution) and external conditions (mainly thermal history conditions here).

\subsubsection{Effects of thermal history and solute redistribution on phase formation in alloys}

Thermal history refers to the change of temperature under the influence of external conditions, which is the external factor inducing alloy transformation and precipitation of new phases. Since the equilibrium condition is ideal, the cooling rate and the undercooling degree are approximately zero. However, in both the casting and LMD process, the alloy cools at a certain speed, and the phase transformation is driven by the 
undercooling. What's more, the undercooling is greater in LMD than that in casting, which leads to the nucleation rate and the amount of precipitated phase increase in LMD. At the same time, the greater cooling rate also causes the elements to not fully diffuse; the growth of precipitates is inhibited, so the LMD particles are smaller, as displayed in Figs. 8 and 9.

Furthermore, under the equilibrium condition, the solute diffusion can be fully carried out, and various possible phases can appear conforming to the lowest Gibbs free energy principles. However, the predicted phases cannot be all observed in the experiments due to the limitation of kinetics, that to say, the atoms cannot fully diffuse to meet the solute condition under the condition of cooling, especially fast cooling. Continuous cooling transformation (CCT) curve can be used to explain the transformation process, as shown in Fig. 13(c).

It is worth mentioning that the temperature at which MC carbide formed is higher than that of Laves, it is inferred that $\mathrm{MC}$ carbides can provide nucleus for Laves to grow up during LMD, therefore, MC are often observed be surrounded by Laves, as shown in Fig. 13(a). Laves phase is a kind of topologically close-packed (TCP) phases. The abovementioned Laves, $\mu$ and $\sigma$ phases are all TCP phases according to Ref. [22]. It should be noted that TCP in this study and in the figure generally refers to Laves phase unless otherwise specified.
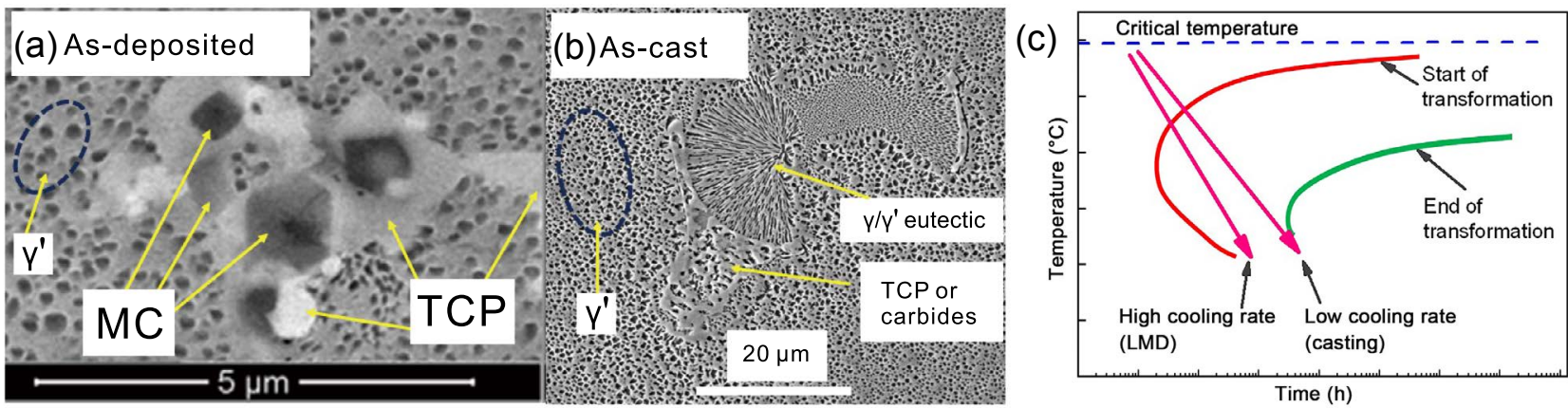

Fig. 13: Typical MC carbides or TCP precipitation in alloy: (a) as-deposited; (b) as-cast; (c) CCT curve

TCP phases are brittle and enriched in refractory elements. The parameters of the processing are chosen to avoid, rather than to promote, the formation of TCP because TCP phases imply a lack of stability, which is detrimental to mechanical behavior. Rapid cooling can inhibit the formation of TCP or alter the morphology of it. So, LMD is a way to eliminate or decrease Laves phase. Comparing with casting, LMD has its advantages to control Laves phases because the as-deposited alloy has smaller PDAS, which forces the size and volume fraction of MC and Laves to be smaller too. For LMD process, $\mathrm{MC}$ and Laves are distributed in small blocks, several microns in size, sometimes chain-like, reaching tens of microns, while in the as-cast alloy, there is a network distribution of tens to hundreds of microns. It is noted that $\gamma / \gamma^{\prime}$ eutectic in the as-cast alloy is very clear, as shown in Fig. 13. The solidification of the as-cast alloy takes more time, the interdendritic region provides not only more solute, but also more room for the formation of TCP. Similar investigation has also been conducted by other researchers to adjust the formation of TCP. For example, in laser solid formed (LSFed) Inconel 718 superalloy, the morphology of Laves phase changes from strip-like to spherelike, and its amount decreases by electromagnetic stirring ${ }^{[30]}$. Both the size and the volume fraction of Laves phase decreased with the increases of the solution temperature ${ }^{[31]}$.

Another unique characteristic of LMD is the elimination of possible defects like freckles, also known as channel segregates, due to so-called "density inversion" ${ }^{[22]}$, a kind of macro segregation which often occurs during casting. It is noted that the critical PDAS for the formation of freckles is $\sim 300 \mu \mathrm{m}$, while that of LMD is $30-45 \mu \mathrm{m}$. LMD technique builds parts by progressively adding small amount of materials with laser melting, and has a very fast solidification rate. The solid-liquid interface sweeps the melt at a very high speed, so there is not enough time for the solid solute to diffuse to the liquid phase, and the phenomenon of solute trap occurs ${ }^{[32]}$. Therefore, the segregation is greatly restrained, and the volume and type of precipitates are also restrained.

\subsubsection{Some exceptional precipitates}

It should be pointed out that the precipitation of phase in the alloy depends on the solute condition, cooling condition or heating condition, that is, thermodynamic condition and kinetic condition. For example, there is no $\mu$ phase in the as-deposited alloy, but the phase is observed in the specimen after longterm aging at $750{ }^{\circ} \mathrm{C}$ for $1,000 \mathrm{~h}$, which exhibits needle shape, as shown in Fig. 14(a). There are also a few phases which are not found in the calculation, but they are observed in the experiment under certain conditions. The discovery of Heusler phase is an example, as shown in Fig. 14(b). It is found in the tensile specimen which is heat treated at $870^{\circ} \mathrm{C}$ for $16 \mathrm{~h}$.

It is known that needle-shaped $\mu$ phase, as mentioned above, is considered to be a harmful phase, which can deteriorate the creep properties of the alloy. In contrast, it has been reported that Heusler phase can improve the properties of the alloy ${ }^{[33,34]}$. There is a certain lattice strain in the phase, and the stress field of lattice strain and dislocation strongly interact with each other, which strongly hinders the movement of dislocation and produces a strengthening effect ${ }^{[34]}$. Therefore, it is worthwhile to deepen the related research to improve the performance of the alloy. 

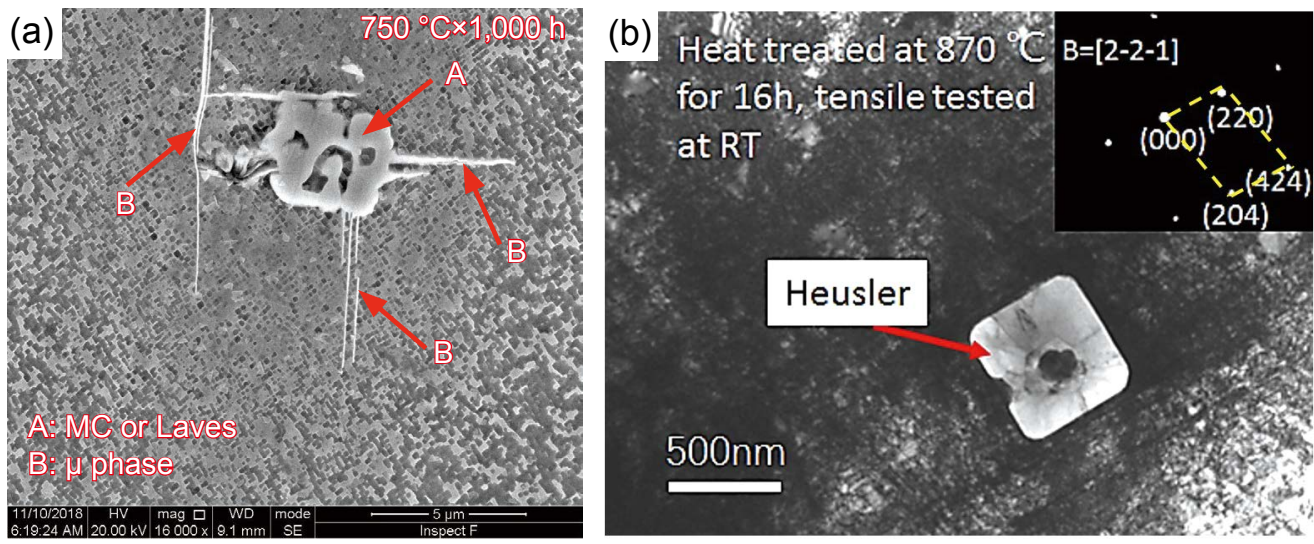

Fig. 14: Precipitated phase of the alloy after heat treatment: (a) $750^{\circ} \mathrm{C} \times 1,000 \mathrm{~h}$; (b) $870{ }^{\circ} \mathrm{C} \times 16 \mathrm{~h}$

\subsection{Reasons for better properties of as-deposited $\mathrm{Ni}$-based superalloy}

The aforementioned narrated remarkable differences in microstructures and mechanical properties between asdeposited and as-cast alloys. The as-deposited alloy has better tensile behavior. The mechanisms could be summarized as follows: (1) Rapid solidification of the LMD process generates fine microstructure with super saturation $\gamma$ matrix in the alloy which plays a significant role in the alloy strength. It is known that solid solution strengthening can raise the value of CRSS to active dislocation slipping. (2) The tiny melting pool accumulation of LMD enables a more uniform microstructure without macro segregation like as-cast, with a far smaller PDAS. (3) The $\gamma / \gamma^{\prime}$ eutectic and TCP phase are phases with lower strength and are prone to form cracks in the bulk alloy. By using the LMD method, finer and discrete $\gamma / \gamma^{\prime}$ eutectic and TCP phase particles are obtained instead of the coarser $\gamma / \gamma^{\prime}$ eutectic easily occurring in as-cast alloy. The continuous brittle TCP phase may be avoidable. By altering the manufacture method from cast to LMD, a brittle-to-ductile transition takes place which is demonstrated by the fractographs in Fig. 11, and the linearly hardening region is extended [Fig. 10(a)].

Finally, it is worth noting that the $\gamma^{\prime}$ volume fraction of the as-deposited specimen is $5 \%-10 \%$ less than that of the as-cast. According to statistical analysis and Thermo-Calc simulation, this means that there is potential space to adjust and control the fraction of the $\gamma^{\prime}$ phase, which is an effective performance regulation method since the alloy mechanical properties correlate very strongly with the sum of the fractions of the strengthening phases ${ }^{[22]}$. Moreover, by refining the $\gamma^{\prime}$ phase, the mechanical performance can also be enhanced. To promote the practical application of the alloy, more investigation should be done in future, including optimization through compositional variations, process control and post processing, to provide a basis for controlling of the microstructure and tailoring of the properties of the alloys.

\section{Conclusions}

In summary, combining differential scanning calorimetry analysis and simulation calculation is a convenient and economical way to investigate a newly designed alloy. Components made by different processing methods may have strikingly different microstructure. LMD is a convenient and effective way to tailor the microstructure and improve properties of a superalloy by controlling the solidification parameters. The main conclusions may be presented as follows:

(1) Basic phase constitution of a Ni-based superalloy specially designed for additive manufacturing is $\gamma$ with FCC crystal structure and $\gamma^{\prime}$ with L12 crystal structure. The $\gamma / \gamma^{\prime}$ interface remains coherent. Other possible phases occupy very low volume fraction. The experimental results agree with the Scheil model more closely than the equilibrium model.

(2) The as-deposited alloy has fine parallel cellular (column) dendrites along the deposition direction with PDAS about $30-45 \mu \mathrm{m}$. The average size of $\gamma^{\prime}$ particles is $100-150 \mathrm{~nm}$, and usually the interdendritic regions have coarser particles. Meanwhile, the as-cast alloy has equiaxed dendrite and its PDAS is $300-500 \mu \mathrm{m}$. The average size of $\gamma^{\prime}$ particles in them are $315 \mathrm{~nm}$ (interdendritic regions) and $208 \mathrm{~nm}$ (dendritic regions), respectively. MC carbides and TCP precipitation, as well as $\gamma / \gamma^{\prime}$ eutectic occur only in the interdendritic regions for both kinds of specimen, but the as-cast has larger values of size and volume fraction.

(3) The as-deposited specimen shows better ultimate tensile stress $(1085.7 \pm 51.7 \mathrm{MPa})$, yield stress $(697 \pm 19.5 \mathrm{MPa})$ and elongation $(25.8 \pm 2.2 \%)$ than that of the as-cast, which are 782.7 $\pm 8.6 \mathrm{MPa}$ (UTS), 616.7 $\pm 16.5 \mathrm{MPa}$ (YS) and 12.6 $\pm 1.2 \%$ (elongation). The fracture of as-deposited specimens occurs in ductile-brittle mixed-mode behavior, while the as-cast exhibits a clear brittle fracture. Reasons for the better properties of as-deposited alloys can be summarized as solid-solutionstrengthened mechanism, fine dendrite microstructure, fine TCP and $\gamma / \gamma^{\prime}$ eutectic microstructure, elimination of macrosegregation, etc.

\section{Acknowledgements}

This work was financially supported by the National Science and Technology Major Project (Y2019-VII-0011-0151), the National Natural Science Foundation of China (No. 51771190). 


\section{References}

[1] Xu J W, Zhao Y S, Tang D Z. Tensile properties of a lowcost first generation single crystal superalloy DD16. High Performance Structure Materials, 2013: 478-482.

[2] Ramakrishnan A, Dinda G P. Microstructure and mechanical properties of direct laser metal deposited Haynes 282 superalloy. Materials Science and Engineering: A, 2019, 748: 347-356.

[3] Zhang $Y$, Zhang $Y W$, Sun $Z$ K, et al. Influence of PPB on crack growthbehavior of PM Ni-based superalloy. Rare Metal Materials and Engineering, 2019, 48(10): 3282-3288. (In Chinese)

[4] Tachibana Y, Ikeshoji T T, Nakamura K, et al. Selective laser melting of Inconel 718 under high power and high scanning speed conditions. In: Shabadi R, Ionescu M, Jeandin M, Richard C, Chandra T (Eds.), Thermec 2018: 10th International Conference on Processing and Manufacturing of Advanced Materials, Paris, France, 2018, 941: 1574-1578.

[5] Chen Y, Guo Y B, Xu M J, et al. Study on the element segregation and Laves phase formation in the laser metal deposited IN718 superalloy by flat top laser and gaussian distribution laser. Materials Science and Engineering: A, 2019, 754: 339-347.

[6] Harrison N J, Todd I, Mumtaz K. Reduction of micro-cracking in nickel superalloys processed by selective laser melting: $\mathrm{A}$ fundamental alloy design approach. Acta Materialia, 2015, 94: $59-68$.

[7] Lu B H, Li D C. Development of the additive manufacturing (3D printing) technology. Machine Building and Automation, 2013, 42(4): 1-4. (In Chinese)

[8] Hao Z B, Ge C C, Li X G, et al. Effect of heat treatment on microstructure and mechanical properties of nickel-based powder metallurgy superalloy processed by selective laser melting. Aata Metallurgica Sinica, 2020, 56(8): 1133-1143. (In Chinese)

[9] DebRoy T, Wei H L, Zuback J S, et al. Additive manufacturing of metallic components - Process, structure and properties. Progress in Materials Science, 2018, 92: 112-224.

[10] Wang F, Wu X H, Clark D. On direct laser deposited Hastelloy $\mathrm{X}$ : Dimension, surface finish, microstructure and mechanical properties. Materials Science and Technology, 2011, 27(1): 344-356.

[11] Zhong $M$ L, Sun $H$ Q, Liu W J, et al. Boundary liquation and interface cracking characterization in laser deposition of Inconel 738 on directionally solidified Ni-based superalloy. Scripta Materialia, 2005, 53(2): 159-164.

[12] Liu W, Li N, Zhou B, et al. Progress in additive manufacturing on complex structures and high-performance materials. Journal of Mechanical Engineering, 2019, 55(20): 128-151+159. (In Chinese)

[13] Song H Y, Lei J B, Xie J C, et al. Laser melting deposition of K403 superalloy: The influence of processing parameters on the microstructure and wear performance. Journal of Alloys and Compounds, 2019, 805: 551-564.

[14] Ramakrishnan A, Dinda G P. Direct laser metal deposition of Inconel 738: Materials Science and Engineering: A, 2019, 740: 1-13.

[15] Moradi M, Hasani A, Beiranvand Z M, et al. Additive manufacturing of stellite 6 superalloy by direct laser metal deposition - Part 2: Effects of scanning pattern and laser power reduction in differrent layers. Optics and Laser Technology, 2020, 131: 106455.

[16] Moradi M, Ashoori A, Hasani A. Additive manufacturing of stellite 6 superalloy by direct laser metal deposition - Part 1: Effects of laser power and focal plane position. Optics and Laser Technology, 2020, 131: 106455.
[17] Gu D D, Meiners W, Wissenbach K, et al. Laser additive manufacturing of metallic components: Materials, processes and mechanisms. International Materials Reviews, 2012, 57(3): 133-164.

[18] Walter C, Hallstedt B, Warnken N. Simulation of the solidification of CMSX-4. Materials Science and Engineering: A, 2005, 397(1-2): 385-390.

[19] Gong L, Chen B, Du Z H, et al. Investigation of solidification and segregation characteristics of cast $\mathrm{Ni}$-base superalloy K417G. Journal of Materials Science \& Technology, 2018, 34(3): 541-550.

[20] Detrois M, Jablonski P D, Antonov S, et al. Design and thermomechanical properties of a $Y^{\prime}$ precipitate-strengthened $\mathrm{Ni}$-based superalloy with high entropy y matrix. Journal of Alloys and Compounds, 2019, 792: 550-560.

[21] Pan J S, Tong J M, Tian M B. Fundamentals of materials science. Beijing: Tsinghua University Press, 1998. (In Chinese)

[22] Reed R C. The superalloys fundamentals and applications. Cambridge: Cambridge University Press, 2006.

[23] Long $H$ B, Liu Y N, Kong D L, et al. Shearing mechanisms of stacking fault and anti-phase-boundary forming dislocation pairs in the $\mathrm{Y}^{\prime}$ phase in Ni-based single crystal superalloy. Journal of Alloys and Compounds, 2017, 724: 287-295.

[24] Yu H, Wang Z T, Zhang B Y, et al. Re-precipitation mechanisms of the $Y^{\prime}$ phase with sphere, near-sphere, cubic, octets and finally-dendrite in as-cast Ni-based superalloys. Journal of Alloys and Compounds, 2021, 876: 160104.

[25] Sindo K. Welding metallurgy. A John Wiley \& Sons, Inc., Publication, 2003.

[26] Szeliga D. Microstructure refinement of single crystal Ni-based superalloy by improvement of thermal radiation shielding in the industrial-scale Bridgman solidification process. International Communications in Heat and Mass Transfer, 2020, 118: 104868.

[27] Segerstark A, Andersson J, Svensson L E, et al. Microstructural characterization of laser metal powder deposited alloy 718 . Materials Characterization, 2018, 142: 550-559.

[28] Liang Y J, Li A, Cheng X, et al. Prediction of primary dendritic arm spacing during laser rapid directional solidification of single-crystal nickel-base superalloys. Journal of Alloys and Compounds, 2016, 688: 133-142.

[29] Acharya R, Bansal R, Gambone J J, et al. A microstructure evolution model for the processing of single-crystal alloy CMSX-4 through scanning laser epitaxy for turbine engine hotsection component repair (Part II). Metallurgical and Materials Transactions: B, 2014, 45 (6): 2279-2290.

[30] Liu F C, Cheng H M, Yu X B, et al. Control of microstructure and mechanical properties of laser solid formed Inconel 718 superalloy by electromagnetic stirring. Optics and Laser Technology, 2018, 99: 342-350.

[31] Zhang W J, Zheng Y S, Liu F G, et al. Effect of solution temperature on the microstructure and mechanical properties of Hastelloy $X$ superalloy fabricated by laser directed energy deposition. Materials Science and Engineering: A, 2021, 820: 141537.

[32] Kurz W, Fisher D J, Li J G, et al. Fundamentals of solidification. Beijing: Higher Education Press, 2010.

[33] Feng Q, Nandy T K, Pollock T M. Observation of a Ru-rich Heusler phase in a multicomponent Ni-base superalloy. Scripta Materialia, 2004, 50(6): 849-854.

[34] Guo J T. Materials science and engineering for superalloys. Beijing: Science Press, 2008. (In Chinese) 